\title{
Analyzing the Position of Safety Culture Education in 2019-2020 Elementary School Textbooks in Iran's Education System
}

\author{
Mojtaba Sarhangi Kadijani', Alireza Araghieh ${ }^{\dagger}$, Pari Sosahabi ${ }^{r}$, Alireza Sadeghi \\ Amir Hossein Mahdizadeh ${ }^{\circ}$
}

Date of submission: 29 Oct. 2020

Date of acceptance: 02 May. 2021

\section{Original Article}

\begin{abstract}
INTRODUCTION: The natural hazard reduction curriculum is incredibly critical in facilitating and improving students' safety culture. Thus, we must attend to the content of textbooks to further comprehend the significance of safety issues regarding the process of student safety. The next step is developing a training program that meets all the fundamental needs of safety education. Hence, this research study strives to evaluate the position of safety culture education in elementary school textbooks.
\end{abstract}

METHODS: This research is a quantitative content analysis borrowing a qualitative approach. The statistical population comprised all books on Persian language and literature, experimental sciences, and social studies in all the six primary levels. Counting was the sampling method in the present study. Experts in curriculum planning and health education confirmed the validity of this research. Moreover, the Scott test obtained a reliability of 0.72 .

FINDINGS: The findings of content analysis in assessing elementary school textbooks based on the Shannon Entropy method indicated that the following indices have the highest frequency and significance: Risk and disaster awareness in 150 samples $\left(\mathrm{W}_{\mathrm{j}}=0.273\right)$, Communication skills, awareness of the environment, and human-environmental interactions with 46 samples $\left(\mathrm{W}_{\mathrm{j}}=0.0666\right)$, On the contrary, the index of child rights aspects with zero cases $\left(\mathrm{W}_{\mathrm{j}}=0\right)$ was the least significant among the indices and components.Findings from the frequency of components revealed that safety culture components were not normally distributed.

CONCLUSION: According to the research findings, we found out that the components in the fields of skill and attitude have received little to no attention. However, nurturing and promoting the capabilities and skills of children in the field of safety are some of the most vital indices of child safety. Contemplating these aspects will assist in properly performing relief, emergency, and law enforcement missions by preventing disasters.

Keywords: Content Analysis; Presumptions of Natural Hazard Reduction; Red Crescent Society; Safety Culture Education; Shannon Entropy.

How to cite this article: Sarhangi Kadijani M, Araghieh A, Sosahabi P, Sadeghi A, Mahdizadeh AH.

Analyzing the Position of Safety Culture Education in 2019-2020 Elementary School Textbooks in

Iran's Education System. Sci J Rescue Relief 2021; 13(2): 149-59.

\section{Introduction}

owadays, natural disasters are allotted a

$\mathrm{N}$

large percentage of government resources and programs. The news media transmits daily information regarding the occurrence of various incidents globally.

Besides, statistics demonstrate the increasing occurrence of accidents around the world. Catastrophes and disasters impose heavy casualties and financial expenses on governments and nations annually (1).

Past experiences and current evidence revealed that the education department suffers the most

1- PhD student, Islamic Azad University, Islamshahr Branch, Curriculum Planning Department, Islamshahr, Iran

2- Associate Professor, Islamic Azad University, Islamshahr Branch, Department of Curriculum Planning, Islamshahr, Iran

3- Assistant Professor, Islamic Azad University, Islamshahr Branch, Department of Philosophy, Islamshahr, Iran

4- Associate Professor, Allameh Tabataba'i University, Department of Curriculum Planning, Tehran, Iran

5- Assistant Professor, Islamic Azad University, Islamshahr Branch, Curriculum Planning Department, Islamshahr, Iran

Correspondence to: Alireza Araghieh, Email: araghieh@iiau.ac.ir 
severe blows alongside other departments in case of disaster outbreaks (2).

Cases such as the 2003 Bam earthquake, the flood in Qom, and the 2017 Kermanshah earthquake pulled the schools and the students apart due to the schools' structural collapse and failure. The most recent and prevalent threat has been the coronavirus global pandemic. There are some issues distressing parents and, even more so, the children and threatening their psychological security (3).

Studies on the impacts of accidents and disasters on children show that accidents can cause extensive disorders in juveniles and their living environment such as home, school, etc. Unforeseen incidents can leave a devastating psychological impact on children. Therefore, children have to be protected from abuse, physical harm, mental trauma, distress, separation from family, etc. at all costs (4).

The United Nations Convention on the Rights of the Child (UNCRC) officially recognized in 1990, explicitly states that every child has the inherent right to life (Article 6) and the right to education (Article 28) (5). This considerable principle requires education.

Findings of a study on post-traumatic stress disorder (PTSD) in children rescued from a tsunami in a southern region of India suggest that PTSD was more prevalent among girls and teenagers who had faced the risk of death. Furthermore, children aged 7 to 14 were more likely to develop the disorder (6).

Zyani et al. (2018), administered a study entitled "What are the Educational Needs of Primary School Children Regarding Accident Prevention?" indicating that most children demonstrated favorable performance and little educational need for accident prevention (7).

In a study titled "Hazard Identification and Risk Assessment through FMEA Method in Tehran 8th District Girls' and Boys' Public Elementary Schools", Bakooie et al. suggested that assessing the hazards and risks at schools could be a constructive and beneficial action to promote student safety and health, especially in elementary schools (8).

Analyzing the contents of 48 elementary school textbooks in the United States, Frager and Kahn concluded that the education provided was inadequate and inefficient. They believed the information delivered assisted the students rather theoretically than practically (9).

Izadkhah and Lisa Gibbs (2015) conducted a qualitative study investigating the state of education regarding natural disasters (earthquakes) in preschool children. They reported that although the Disaster Preparedness Association in Iran has been established since 1990, unfortunately, no substantial effort has taken place to execute education for children to date. The findings of the study, utilizing "content analysis" as the research technique, assessed the characteristics observed in children's drawings: using colors to demonstrate anxiety and fear, using body parts to take shelter from earthquakes, offering assistance during natural disaster episodes, and using suitable (safe) and unsuitable (unsafe) places to seek shelter. He pointed out that that was a primary study because it explored children's perceptions and attained knowledge regarding earthquakes (10).

Mojdeh Vaziri and Sheida Jahani (2006) organized a study called "Citizenship Skills Required by Primary School Students in the Earthquake-Stricken City of Bam". The findings suggested that the skills required by students in the forenamed period and circumstance were:

1) problem-solving,

2) decision-making,

3) effective social interaction,

4) appropriate emotional responses,

5) self-awareness,

6) global citizenship competence,

7) professional capabilities,

8) life management,

9) information technology,

10) critical thinking (11).

Given the role of safety at the time of hazard occurrence and a crucial resource in cultural, social, and personal development, as well as the sensitivity of the elementary period in the formation of habits and behavior, giving attention to this urgent matter is one of the vital tasks of any government and education system. To achieve this valuable goal, they must teach safety culture at schools. In other words, schools and textbook contents are the best grounds for operationalizing disaster safety and preparedness education.

All that being said, it seems that effective safety training programs in our country's education system have paid little attention to 
cultivating deep mental processes and influencing students' actions and emotions. Likewise, the researchers have shown little interest in experimenting in this field.

Therefore, the question that arises in this regard is: "What are the components and themes of risk reduction education in the domains of knowledge, skills, and attitudes in textbook contents"?

This study attempts to assess and analyze the components of "disaster risk reduction" education in the curriculum, specifically in elementary schools.

\section{Methods}

The method of the present study is a quantitative content analysis employing a qualitative approach in which textual elements are counted and there are 7 steps shown in Figure 1 (12).

In addition to the appearance-related aspects and quantitative aspects, the textbooks also incorporate qualitative features, which often form the "invisible" and unseen characteristics of the educational contents (13).

In the present study, we used the objectives of the components of safety culture education in Bloom's cognitive domains (knowledge, attitude, skills). This set has 21 indices and 89 components. However, the experts conducted an evaluation, and since the scope of research was limited to elementary schools, 14 indices with 64 components, verbally and semantically closer to this period, were selected.

The statistical population comprised all books of Persian language and literature, experimental sciences, and social studies from the first to the sixth grade of elementary school (2020-2021). The textbooks for the first grade of elementary school included written sections, illustrations, exercises, and questions. Hence, a page analysis unit was appointed to cover the lessons, questions, exercises, and illustrations. In the current study, sample count was the method we used.
Then the data were analyzed using the Shannon entropy method. So that first the message was counted in terms of frequency in terms of categories and then based on the data in the frequency table, the following steps were performed in order:

The first step: The frequency table matrix of the frequency table should be normalized to use this relation:

$P_{i j}=\frac{F_{i j}}{\sum_{i=1}^{m} F_{i j}} \quad(i=1.2 .3 \ldots . m . j=1.2 \ldots . n)(1)$

$\mathrm{F}_{\mathrm{ij}}=$ component frequency

$\mathrm{P}_{\mathrm{ij}}=$ normalized frequency matrix

$\mathrm{I}=$ respondent number

$\mathrm{N}=$ number of components

$\mathrm{M}=$ number of respondents

$\mathrm{J}=$ component number

The second step: The information load of each category is calculated and placed in the relevant columns. The following relation is used for this purpose:

$$
\begin{array}{r}
E_{j}=-k \sum_{i=1}^{m}\left[p_{i j} l_{n} p_{i j}\right] \quad(i=1.2 .3 \ldots . j \\
=1.2 \ldots . n) \quad k=\frac{1}{\operatorname{LnM}(2)}
\end{array}
$$

$E_{j}=$ information load

$\mathrm{P}=$ normalized frequency matrix

$\mathrm{I}=$ respondent number

$\mathrm{M}=$ number of respondents

$\mathrm{J}=$ component number

$\mathrm{Ln}=$ logarithm

$\mathrm{N}=$ number of components

The third step: Using the information load of the markers, the significance coefficient of each marker is calculated. The higher the information load, the higher the value of $\mathrm{W}_{\mathrm{j}}$.

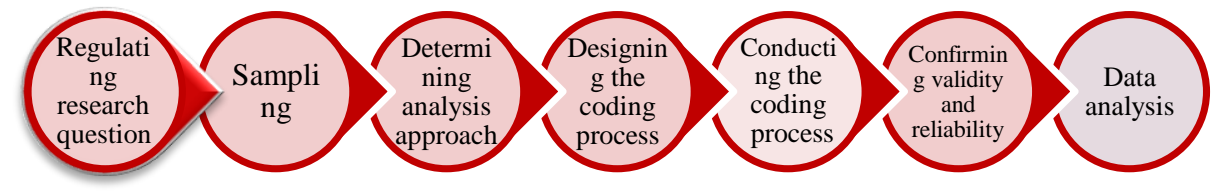

Figure 1. Steps of quantitative content analysis 


$$
\begin{gathered}
W_{j}=\frac{E_{j}}{\sum_{i=1}^{m} E_{j}}(3) \\
\mathrm{E}_{\mathrm{j}}=\text { information load } \\
\mathrm{W}_{\mathrm{j}}=\text { degree of importance } \\
\mathrm{J}=\text { component number }
\end{gathered}
$$

It should be pointed out that in the calculation of $E_{j}$, the values of $P_{i j}$, which is equal to zero, have been replaced with the very small number of 0.00001 due to the errors and infinite answers in mathematical calculations. $\mathrm{W}_{\mathrm{j}}$ is an index that determines the significance coefficient of each category in a message, according to the form of respondents. On the other hand, in accordance with the $\mathrm{W}$ vector, the categories resulted from the message are also ranked (14). Thus, in Shannon's method, the obtained data is normalized. It provides more information on how to interpret the data. Furthermore, the validity of the safety components was assessed employing the viewpoints of 3 curriculum experts and specialists and 3 experts in safety education. The reliability was obtained equal to 0.72 through the Scott method.

\section{Findings}

The findings of the present study are presented in the following tables based on the performed analyses. The data were normalized using the Shannon entropy method. First, the frequency of sub-indices and the main index or components of each book were specified. Then, the information load of the data was obtained. Next, according to the third step of the aforementioned method, findings were reexamined and analyzed in three domains of knowledge, skills, and attitude, the results of which are presented separately as follows:

By analyzing the factors and components of safety education in the textbooks employed in elementary school, the findings extracted from the content analysis of the components of safety

\begin{tabular}{|c|c|c|c|c|c|c|c|c|}
\hline Components & Themes & 3 & vi & 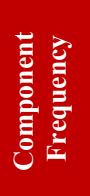 & 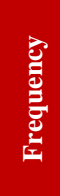 & 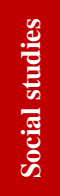 & 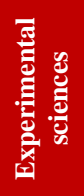 & 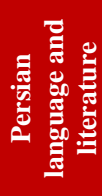 \\
\hline \multirow[t]{10}{*}{$\begin{array}{l}\text { Awareness of natural and man- } \\
\text { made hazards and disasters }\end{array}$} & $\begin{array}{l}\text { Earth movements, Landslides, Soil } \\
\text { erosions, Earthquakes, Volcanoes }\end{array}$ & 0.027447 & 0.87309 & 150 & 19 & 5 & 11 & 3 \\
\hline & $\begin{array}{c}\text { Climate changes, Floods, Hurricanes, } \\
\text { Tsunamis, Droughts }\end{array}$ & 0.029237 & 0.93002 & & 23 & 5 & 6 & 12 \\
\hline & Deforestation, Bushfires & 0.018214 & 0.57939 & & 6 & 2 & 0 & 4 \\
\hline & Blizzards, Avalanches, Ice frosts & 0.030876 & 0.98214 & & 7 & 2 & 2 & 3 \\
\hline & $\begin{array}{l}\text { Diseases (epidemics), pollutions (sound } \\
\text { and environmental) }\end{array}$ & 0.027127 & 0.86289 & & 37 & 6 & 22 & 9 \\
\hline & Wars, Accidents & 0.019795 & 0.62968 & & 38 & 18 & 0 & 20 \\
\hline & Famines, Migration & 0.039876 & 0.98214 & & 7 & 2 & 3 & 2 \\
\hline & Previous disasters & 0.030187 & 0.96023 & & 5 & 2 & 2 & 1 \\
\hline & Specific local hazards & 0.029752 & 0.96439 & & 4 & 1 & 2 & 1 \\
\hline & Seasonality of some disasters & 0.029752 & 0.94639 & & 4 & 1 & 1 & 2 \\
\hline \multirow[t]{3}{*}{$\begin{array}{l}\text { Concepts and methods of } \\
\text { disaster risk reduction }\end{array}$} & Risk, fear, vulnerability & 0.023129 & 0.73572 & 26 & 17 & 5 & 1 & 11 \\
\hline & $\begin{array}{l}\text { The concept of "safety culture" and its } \\
\text { applications in life }\end{array}$ & 0.018124 & 0.57939 & & 9 & 3 & 6 & 0 \\
\hline & Economic issues of disaster risk reduction & 1.1906 & 3.805 & & 0 & 0 & 0 & 0 \\
\hline \multirow[t]{3}{*}{$\begin{array}{l}\text { Awareness of the environment } \\
\text { and environmental/human } \\
\text { interactions }\end{array}$} & $\begin{array}{l}\text { The negative impact of human misconduct } \\
\text { in the environment on disasters }\end{array}$ & 0.024691 & 0.78541 & 46 & 19 & 9 & 9 & 1 \\
\hline & $\begin{array}{l}\text { The positive impact of optimal human } \\
\text { performance in the environment on disasters }\end{array}$ & 0.025225 & 0.80241 & & 16 & 7 & 8 & 0 \\
\hline & Basic info on safety precautions & 0.016768 & 0.53337 & & 11 & 3 & 8 & 0 \\
\hline \multirow[t]{3}{*}{$\begin{array}{l}\text { Distinctive and disproportionate } \\
\text { impact of hazards on individuals }\end{array}$} & $\begin{array}{l}\text { Students understand that changes in the } \\
\text { circumstances are generally man-made. }\end{array}$ & 7.907 & 2.505 & 18 & 6 & 6 & 0 & 0 \\
\hline & $\begin{array}{c}\text { Awareness of the resurgence of disasters } \\
\text { during climate changes }\end{array}$ & 0.01712 & 0.54458 & & 7 & 0 & 5 & 2 \\
\hline & $\begin{array}{l}\text { The disproportionate impact of disasters on } \\
\text { different communities }\end{array}$ & 1.1906 & 3.805 & & 0 & 0 & 0 & 0 \\
\hline
\end{tabular}
education in hazards in the domain of knowledge are presented in Table 1.

Table 1. Frequency, the amount of information load, and significance coefficient of components and indices 


\begin{tabular}{|c|c|c|c|c|c|c|c|c|}
\hline \multicolumn{9}{|c|}{ Table 1. Continued } \\
\hline \multirow{7}{*}{$\begin{array}{l}\text { Duties of social and service } \\
\text { institutions at times of disaster }\end{array}$} & $\begin{array}{l}\text { The disproportionate distribution of } \\
\text { "climate change" around the world }\end{array}$ & 0.019835 & 0.63094 & & 4 & 0 & 2 & 2 \\
\hline & $\begin{array}{c}\text { Children being at a higher risk at times of } \\
\text { disaster }\end{array}$ & 7.9107 & 2.505 & & 1 & 0 & 0 & 1 \\
\hline & $\begin{array}{l}\text { The impact of gender, and social and } \\
\text { cultural status of the child on the damage } \\
\text { caused by disasters }\end{array}$ & 1.1906 & 3.805 & & 0 & 0 & 0 & 0 \\
\hline & Fire department & 0.030967 & 0.98506 & 21 & 8 & 3 & 3 & 2 \\
\hline & Emergency services & 0.019835 & 0.63094 & & 4 & 2 & 2 & 0 \\
\hline & The Red Crescent Society & 0.016092 & 0.51187 & & 4 & 3 & 1 & 0 \\
\hline & The police force & 0.030187 & 0.96023 & & 5 & 2 & 1 & 2 \\
\hline \multirow[t]{3}{*}{$\begin{array}{l}\text { Aspects of child rights at times } \\
\text { of disaster }\end{array}$} & $\begin{array}{l}\text { Awareness of human rights and child rights } \\
\text { legislation at times of disaster }\end{array}$ & 1.1906 & 3.805 & 0 & 0 & 0 & 0 & 0 \\
\hline & $\begin{array}{l}\text { following disasters, e.g., the impacts of } \\
\text { disasters and migration due to the } \\
\text { environment }\end{array}$ & 1.1906 & 3.805 & & 0 & 0 & 0 & 0 \\
\hline & $\begin{array}{l}\text { Awareness of how to use the rights and } \\
\text { responsibilities to reduce the hazards at } \\
\text { times of disaster }\end{array}$ & 1.1906 & 3.805 & & 0 & 0 & 0 & 0 \\
\hline
\end{tabular}

The findings in Table 1 were obtained from reviewing 16 volumes of books on Persian, experimental sciences, and social studies from the first to the sixth year of elementary school, which comprised a total of 1677 pages.

Out of 261 frequencies, the risk and disaster awareness index had the highest frequency with 150 cases. The lowest value was linked to the total component of child rights in hazards with zero frequency, implying how the significance of child rights during catastrophes is left disregarded.

Other cases encompass 26 cases and concepts of risk and hazard, 46 cases of interaction between the environment and humans, 18 cases of differential and disproportionate impacts of individual risks, and 21 cases of social and service institutions.

Analysis results of the factors and components of safety education in the textbooks studied in elementary schools and the results extracted from the content analysis of the safety culture components in hazards in the domain of skills are presented in Table 2.

The findings in Table 2 display a total of 141 frequencies (skills). 44 items are of cognitive and critical thinking skills, 37 items are of selfprotection and self-management skills, 29 items are of communication and personal interaction skills, and 31 items are of practical skills. The skills for implementing preventive and safety measures in the face of hazards in the classroom, school, home, and the community had the highest frequency with 21 cases. Skill indices of collecting, receiving, expressing, and presenting information on reducing the risk of disaster with zero frequency and the first aid index with a frequency of one had the lowest frequency levels. Although the two aforementioned indices must be taught, no education is yet provided regarding them.

We analyzed safety education factors and components of elementary school textbooks. The findings extracted from the content analysis of safety education components in the face of hazards regarding the attitude domain are presented in Table 3.

The findings in Table 3 display a total of 84 frequencies (attitudes). 21 items of the inherent value of nature, 34 items of compassion, empathy, cooperation, and responsibility, 15 items of self-confidence and caution, and 14 items of harmony with the environment are mentioned. The indices of respect for the inherent value of nature, humans, and protection of the natural environment had the highest frequency with 17 cases. Other indices, e.g., respect for the rights of others, time to diminish the risk of catastrophes, and a sense of responsibility and cooperation for those who live far away and are exposed to threats and crises were the least significant indices with zero frequency.

The results concerning the significance coefficient $\left(\mathrm{W}_{\mathrm{j}}\right)$ in Tables 1,2 , and 3 indicate that the highest significance coefficient is associated with hazard awareness and communication skills and interpersonal interaction with $\mathrm{W}_{\mathrm{j}}$ values of 0.273 and 0.100820 , respectively. The lowest 
Table 2. Frequency, amount of information load/significance coefficient of components and indices (skills domain)

\begin{tabular}{|c|c|c|c|c|c|c|c|c|}
\hline Components & Themes & $\mathrm{W}_{j}$ & $\mathrm{E}_{j}$ & 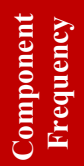 & 冚 & कू & 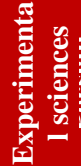 & 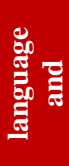 \\
\hline \multirow[t]{6}{*}{$\begin{array}{l}\text { Cognitive and critical } \\
\text { thinking skills }\end{array}$} & $\begin{array}{l}\text { Ability to recognize and interpret signs and } \\
\text { signals of imminent danger }\end{array}$ & 0.020906 & 0.66501 & \multirow[t]{6}{*}{44} & 20 & 3 & 15 & 2 \\
\hline & $\begin{array}{l}\text { Ability to think creatively and divergently } \\
\text { (acting beyond the prescribed frameworks at } \\
\text { times of disaster) }\end{array}$ & 0.026225 & 0.8352 & & 11 & 6 & 1 & 4 \\
\hline & $\begin{array}{l}\text { Ability to think creatively and laterally to } \\
\text { identify opportunities in crises }\end{array}$ & 1.1906 & 3.805 & & 0 & 0 & 0 & 0 \\
\hline & $\begin{array}{l}\text { Ability to make judgments at unfortunate } \\
\text { conditions of disasters }\end{array}$ & 0.019835 & 0.63094 & & 2 & 1 & 0 & 1 \\
\hline & $\begin{array}{l}\text { Ability to use oral, written, and visual media to } \\
\text { detect disasters }\end{array}$ & 0.029752 & 0.94639 & & 4 & 1 & 2 & 1 \\
\hline & $\begin{array}{l}\text { Having the skills to prevent threats and hazards } \\
\text { through effective information management }\end{array}$ & 0 & 0 & & 7 & 3 & 0 & 2 \\
\hline \multirow[t]{4}{*}{$\begin{array}{l}\text { Self-protection and self- } \\
\text { management skills }\end{array}$} & $\begin{array}{l}\text { Having the necessary practical skills to protect } \\
\text { oneself before, during, and after disasters }\end{array}$ & 0.028737 & 0.9151 & \multirow[t]{4}{*}{37} & 21 & 3 & 9 & 9 \\
\hline & $\begin{array}{l}\text { Having skills for collecting, receiving, } \\
\text { expressing, and providing information on } \\
\text { disaster risk reduction }\end{array}$ & 1.1906 & 3.805 & & 0 & 0 & 0 & 0 \\
\hline & First-aid skills & 7.907 & 2.505 & & 1 & 0 & 1 & 0 \\
\hline & Health-related skills & 0.014319 & 0.4555 & & 15 & 3 & 12 & 0 \\
\hline \multirow[t]{6}{*}{$\begin{array}{l}\text { Communication skills } \\
\text { and interpersonal } \\
\text { interaction }\end{array}$} & $\begin{array}{l}\text { Ability to communicate and convey what one } \\
\text { has learned about disasters to family and } \\
\text { community }\end{array}$ & 7.907 & 2.505 & \multirow[t]{6}{*}{29} & 2 & 2 & 0 & 0 \\
\hline & $\begin{array}{c}\text { Effective listening skills in the event of a } \\
\text { disaster }\end{array}$ & 0.018214 & 0.57939 & & 3 & 2 & 0 & 1 \\
\hline & $\begin{array}{c}\text { Ability to express opinions and feelings about } \\
\text { hazards, disasters, and disaster risk reduction } \\
\text { with peers, teachers, family members, and the } \\
\text { community }\end{array}$ & 0.029752 & 0.94639 & & 4 & 2 & 1 & 1 \\
\hline & $\begin{array}{l}\text { Ability to work collaboratively with others to } \\
\text { reduce disaster risk }\end{array}$ & 0.019259 & 0.61261 & & 5 & 3 & 2 & 0 \\
\hline & $\begin{array}{l}\text { Skills to respond effectively and have } \\
\text { appropriate emotional reactions at times of } \\
\text { disaster }\end{array}$ & 0.019259 & 0.61261 & & 5 & 3 & 0 & 2 \\
\hline & $\begin{array}{l}\text { Ability to empathize with those at risk and } \\
\text { affected by disasters }\end{array}$ & 0.014319 & 0.4555 & & 10 & 8 & 0 & 2 \\
\hline \multirow[t]{4}{*}{ Practical skills } & $\begin{array}{l}\text { Ability to cooperate in the environment to } \\
\text { make changes commensurate with disasters }\end{array}$ & 0.018214 & 0.57939 & \multirow[t]{4}{*}{31} & 3 & 2 & 1 & 0 \\
\hline & $\begin{array}{l}\text { Ability to share accident prevention measures } \\
\text { using electronic and traditional media such as } \\
\text { shows, art, letters, gatherings, and participation } \\
\text { in public meetings }\end{array}$ & 0.019542 & 0.61261 & & 7 & 3 & 0 & 4 \\
\hline & $\begin{array}{l}\text { Skills to implement risk prevention and safety } \\
\text { measures in the classroom, school, home, and } \\
\text { community }\end{array}$ & 0.030647 & 0.97488 & & 21 & 9 & 7 & 5 \\
\hline & $\begin{array}{l}\text { Skills needed to participate in early warning } \\
\text { and emergency evacuation exercises }\end{array}$ & 1.1906 & 3.806 & & 0 & 0 & 0 & 0 \\
\hline
\end{tabular}


Table 3. Frequency, amount of information load / and significance coefficient of components and indices (attitude domain)

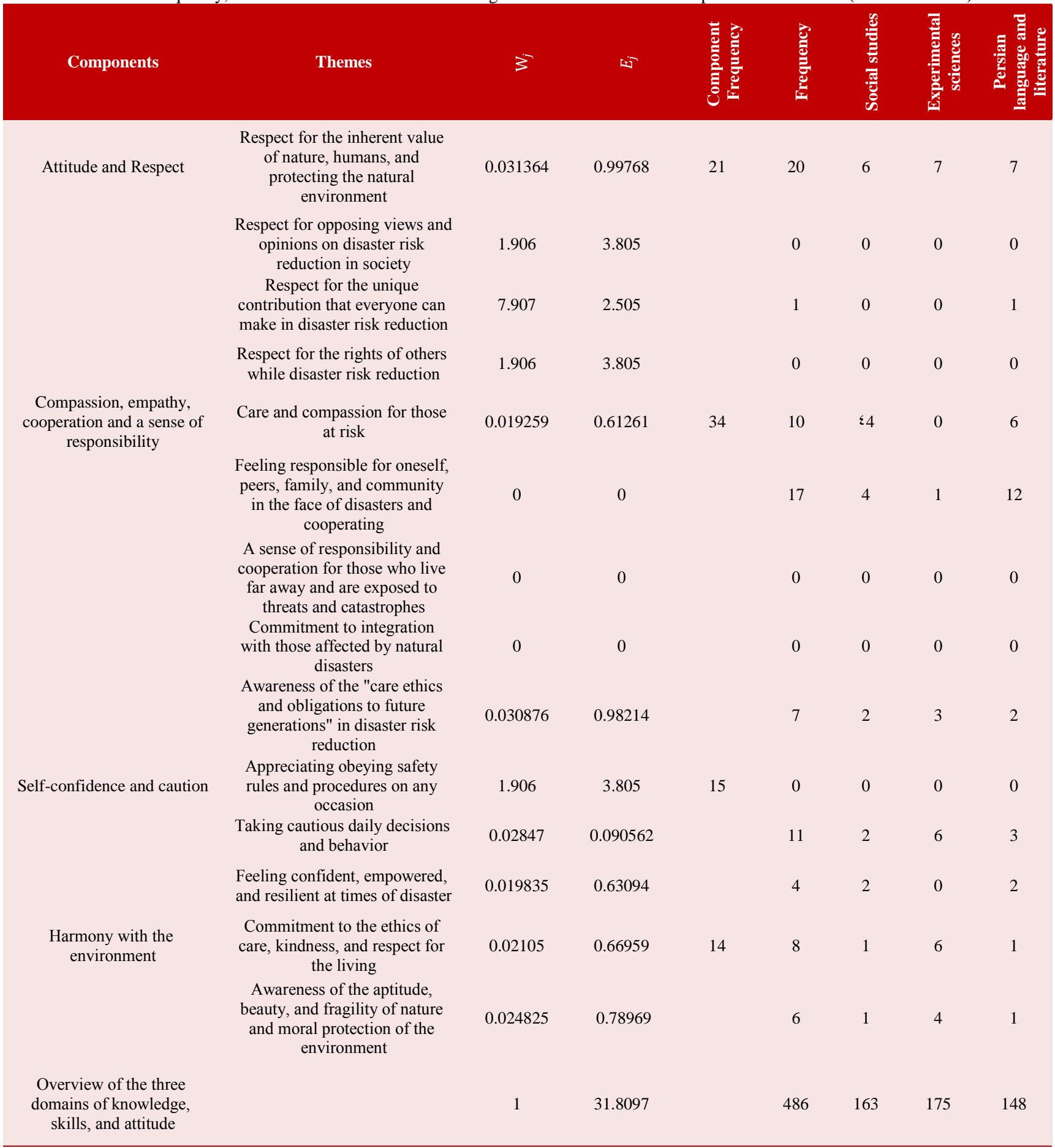

Table 4. The significance of safety culture education in elementary school textbooks of Persian language and literature, experimental sciences, and social studies

\begin{tabular}{cccc}
\hline $\begin{array}{c}\text { Cognitive } \\
\text { Domains }\end{array}$ & Attitude & Skills & Knowledge \\
\hline $\begin{array}{c}\text { Significance } \\
\text { Coefficient }\left(\mathrm{W}_{\mathrm{j}}\right)\end{array}$ & 0.17568 & 0.30899 & 0.51533 \\
\hline
\end{tabular}

significance coefficient is for child rights in disasters and attitude and respect with $\mathrm{W}_{\mathrm{j}}$ values of 0 and 0.3130 , respectively.

Moreover, out of a total of 486 samples (175 books on experimental sciences, 148 on Persian language literature, and 163 on social studies) were significance coefficient is for child rights in disasters and attitude and respect with $\mathrm{W}_{\mathrm{j}}$ values 
of 0 and 0.3130 , respectively.

Moreover, out of a total of 486 samples (175 books on experimental sciences, 148 on Persian examined for the key concepts of safety culture.

Furthermore, the results regarding the frequency of components revealed that safety culture components were not normally distributed. Some components have received more attention than others.

The central question is: "How well are the components and themes of hazard reduction education contemplated in the domains of knowledge, skills, and attitude"?

The results obtained from the content analysis of safety education components in the domains of knowledge, skills, and attitude are presented in Table 4.

Analyzing the results in Table 4 suggests that among the general domains, the most significant factor is from the knowledge domain (0.51533) and the least significant factor is from the attitude domain (0.17568). According to the Shannon Entropy method, the larger a category's information load is, the higher the significance level $\left(\mathrm{W}_{\mathrm{j}}\right)$ will be. Therefore, the knowledge domain is the most important element in primary school textbooks.

\section{Discussion and Conclusion}

This study aimed to assess the contents of elementary school textbooks to evaluate how much they attend to hazard reduction and safety culture promotion. The samples were evaluated as 14 components and 64 indices in 3 categories of Persian language and literature, experimental sciences, and social studies.

These components are as follows: awareness of natural and man-made hazards and disasters, concepts and methods of disaster risk reduction, awareness of the environment and environmental/ human interactions, distinctive and disproportionate impacts of hazards on individuals, tasks of social and service institutions against disasters, aspects of child rights in disasters, cognitive and critical thinking skills, self-defense and self-management skills, communication and interpersonal skills, practical skills, attitude and respect, compassion, empathy, cooperation and sense of responsibility, self-confidence and caution, and harmony with the environment.

The findings confirmed little attention is given to safety culture and hazard education in the language literature, and 163 on social studies) were

elementary school curriculum, while prior studies had highlighted the matter's importance in academia.

In their research study, Bakooi et al. stressed that hazard and risk assessment in schools can be a beneficial and appropriate measure in enhancing the health and growth of students, especially in elementary school. After analyzing 48 elementary school textbooks in the United States, Frager and Kahn concluded that the instruction provided was inadequate and inefficient. Furthermore, they suggested the knowledge provided for the students was more theoretical than practical. Besides, the findings of the present study are compatible with those of Izadkhah (10). Unfortunately, no extensive measure has been taken to implement fitting education for children so far.

The current study, whose research method was "content analysis", evaluates the perceptions and knowledge of children who had been taught about earthquakes.

Moreover, a research study (4) conducted in Botswana (West Africa) on establishing riskreduction education into elementary school curricula has also indicated that the government and education policymakers had no plans to take action. Therefore, there are only a few cases of safety culture education in textbooks.

For instance, there is the textbook of experimental sciences for the sixth grade of elementary school (2019). The section titled A Journey to the Center of the Earth is the most influential and significant unit spreading awareness of hazards and disasters (nature awareness). This unit debates issues such as the interior structure of the earth, which acts as a prelude to lessons about volcanoes and earthquakes. Shortly after, the subject of earthquakes is mentioned in the sixth unit. The unit called Dynamic Earth is an opportunity for the student to learn about two incredibly hazardous natural disasters, particularly the earthquakes that occur annually in all regions of the vast country of Iran and causing unsalvageable human casualties and financial losses for the people (15).

The sixth-grade experimental sciences teacher's book describes an earthquake and its 
scales (Richter and Mercalli) on pages 46 and 47. Then, citing Iran's previous earthquakes in recent years, it manages to elaborate on awareness of previous incidents and disasters, although not detailed enough (16).

Another climactic case in disaster education and fairly placed in the knowledge domain is the nineteenth lesson of the fourth-grade textbook of social studies, which deals with the environment, how to take care of it, and the positive and negative impacts of humans on the environment. Page 86 mentions the negative influence of humans on the environment. "Factories and automobiles inject chemicals and toxins into the environment, polluting water, soil, and air. The spread of waste in the environment harms the lives of all the living and plants." (17).

Other promising cases are lessons 17 and 23 in the third-grade social studies textbook, providing instructions regarding identifying and taking safety measures at home. Then, they introduce the "Fire Department" as a social institution, its duties, and how to contact the relief units. The twenty-third lesson of the book called "Street Safety" can be implicitly associated with the risks of traffic collisions. Next, it describes the road signs and traffic lights (18).

"On the street, it's best to cross where there is a pedestrian crosswalk system. When you reach the crosswalk or corner, walk out to the edge of the road and stop. Double-check that the road is clear before you cross. Look to the left first because traffic will be closer to you on that side. Then, check to your right again when you reach the center of the road, just in case a car is coming. If there was no car approaching, cross cautiously. Remember that we should never run to the middle of the street".

Another case in the attitude domain is the principles of "assistance, empathy, cooperation, and responsibility". With the new approach that curriculum designers have carried in the overt and covert textbook curricula, there are several items of the aforementioned themes present. Although according to the analysis, none of the 27 cases (17 cases of assistance and empathy and 10 cases of cooperation and responsibility) did directly mention disasters and risks, given the generality of these themes, they can be considered as attitudes employed in disasters.

The findings of the research by Ghahramani et al. (19) and Hossein Khani (20) also indicate that teaching health components to students is not enough to change their attitudes. In addition, they do not have the skills required to employ it.

Therefore, there are instructive materials on various aspects of safety culture in the elementary school curriculum. However, they are limited.

There are also considerable and intriguing deficiencies. For instance, in the seventeenth lesson of the third-grade social studies textbook, which was previously mentioned and offers incredibly decent content about heaters and gas types, there is a substantial issue regarding how the content of the lesson is organized and presented.

There are many general and specific topics and goals in Persian language and literature lessons. One of the most crucial tasks of this book is to teach "safety culture". It can play an extremely advantageous role in terms of culture building. Unfortunately, this potential has gone to waste. The themes of assistance and empathy as well as cooperation and responsibility are overlooked as subsets of themes such as war.

The sixth lesson of the third-grade Persian language and literature book (The Devotees) is about Riz Ali Khajavi and Hassan Omidzadeh. Riz Ali's article narrating how he drew the train driver's attention to the landslide could have been linked to safety culture. Although the story revolves around landslide rubble, it conveys a culture of self-sacrifice, not safety.

Considering that culture-building is one of the most significant branches of disaster risk reduction, other hazards being no exception to this principle, the prevailing atmosphere in textbooks, especially those of the Persian language and literature can unravel this issue.

A more detailed evaluation shows that curriculum designers are more focused on safety culture in the final years of elementary school and higher degrees. The subjects are attended more competently. Meanwhile, considering the approximate rate of twenty thousand elementary school dropouts (21) practically a large number of students will be deprived of disaster risk education.

Another point that has to be investigated in content creation is raising student awareness of human rights, child rights, and the responsibilities of children at times of emergency before the authorities and the human and international communities. 
In recent years, the fourth-grade Persian language textbook (2011) titled "Children Have the Right to ..." stated a part of the Universal Declaration of the Rights of the Child, described and defined some organizations, e.g., UNESCO, UNICEF, and the United Nations and the relationship between them. It also labeled Iran as a country that has always been at the forefront of partnership, cooperation, and peace. In the end, it quoted two verses from Sa'adi's famous Bani Adam poem: "Human beings are members of a whole, in the creation of one essence and soul." (22).

This case revealed the hidden depth of curriculum content design. However, this lesson was completely removed from the Persian language and literature curriculum from the academic year of 2014-2015 for unknown reasons.

Eventually, while comparing the components extracted from the samples with the components regarded by UNESCO in safety culture education, some of the topics taught in the lessons could cover the components. Yet some other components, a few of which were discussed in this paper, e.g., awareness of child rights aspects, the greater vulnerability of children in the face of disasters, teaching the concepts of risk, hazard, exposure, effective skills (responding to emotions in the event of disasters), communication and interpersonal interaction skills, first aid skills, commitment to equality, justice, and unity, participation in promoting safety culture, self-confidence, caution, and respect for oneself, the environment and others affected by disasters have been ignored despite their drastic prominence.

\section{Acknowledgments}

The authors would like to express their gratitude to all those who contributed to the conduction of this research project.

\section{Conflict of Interests}

Authors declared no conflict of interests regarding the publication of the present study.

\section{References}

1. Khanakeh H. Hospital readiness in accidents and disasters in the national program. Tehran: University of Social Welfare and Rehabilitation
Sciences Press; 2013. [In Persian].

2. Selby D, Kagawa F. Disaster risk reduction in school curricula: case studies from thirty countries. Geneva, Switzerland: United Nations Children Fund; 2012. P. 45-51.

3. Shirzad B. The role of safe schools in the third millennium. Conference on new methods in school management in the third millennium, Kermanshah, Islamic Azad University, Kermanshah, Iran; 2011. [In Persian].

4. Mutasa S, Coetzee C. Exploring the use of experiential learning in promoting the integration of disaster risk reduction into primary school curriculum: a case of Botswana. J Dis Risk Stud 2019; 11(1): 1-8.

5. Maarefvand M, Eynolyagheen N, Aghakhan M. Protecting children in crisis situations caused by disasters. The First Symposium on the Role of Assistance in Natural Disasters, Colombia, South America; 2010.

6. Kamali M, Panahi H, Gilani O, Azadikhah Haghighat A, Shams Najafi ZS, Modarresi S. Predicting post-traumatic stress disorder severity from emotional intelligence and coping strategies in PTSD patients. J Police Med 2015; 4(1): 39-48.

7. Ziani F. Educational needs of primary school children about accident prevention. Iran J Nurs 1995; 9(10): 36-41.

8. Bakooie Katrini M, Haji Mirzahosseini SA, Nasr Abadi M. Hazards identification and risk evaluation through FMEA method in Tehran 8th district girls and boys' public primary schools. J Environ Sci Technol 2018; 20(1): 157-64.

9. Frager AM, Kahn A. How useful are elementary school health textbooks for teaching about hearing health and protection? Language Speech Hear Serv Sch 1988; 19(2): 175-81.

10. Izadkhah YO, Gibbs L. A study of preschoolers' perceptions of earthquakes through drawing. Int $\mathbf{J}$ Disaster Risk Red 2015; 14: 132-9.

11. Vaziri M, Jahani S. Required citizenship skills for students in the earthquake city of Bam. J Educ Innovations 2006; 5(17): 163-82. [In Persian].

12. Khanifar H, Moslemi N. Fundamental qualitative research methods: new and practical approach. Tehran, Iran: Negahe Danesh Publications; 2017. P. 86-95. [In Persian].

13. Hassanmoradi N. Content analysis of textbook. Tehran: Aij Press; 2020. P. 137-50. [In Persian].

14. Azar A. Development of Shannon entropy method for data processing in content analysis. J Hum AlZahra Univ 2001; 11(37-38): 1-8.

15. Ahmadi A, Ansari Rad P, Bazoobandi MH. Science textbook, Sixth grade elementary. $9^{\text {th }}$ ed. Tehran: Offset Press; 2020. [In Persian].

16. Guide for teachers of experimental sciences. $6^{\text {th }}$ ed. Tehran: General Office for Supervision of 
Publication and Distribution of Educational Materials; 2019. P. 46-7. [In Persian].

17. Partoee Moghadam A, Jahan Ara N, Sangari MR. Social studies, fourth grade. Tehran: Iran Textbook Publishing Press; 2019. P. 86. [In Persian].

18. Falahian N, Malek Mahmoudi N. Social studies textbook, third grade elementary. Tehran: Iran Textbook Publishing Company Press; 2019. P. 74. [In Persian].

19. Ghahramani L, Heidarnia A, Babaei NM. The effect of puberty health education on health behavior of high school female students in Shahrakh. Iran South Med J 2008; 11(1): 61-8.

20. Hossein Khani N. Study of health behaviors of senior nursing students regarding risk factors of coronary artery disease. [PhD Dissertation]. Tehran: Tehran University of Medical Sciences; 1992. [In Persian].

21. Iranian Students' News Agency. Available at: URL: https://www.isna.ir/news/93052110661/; 2020. [In Persian].

22. Arjmand Rashidpour Z, Amirabadi T, Zolfaghari A. Let's read the fourth Persian book of primary school. $9^{\text {th }}$ ed. Tehran: General Directorate of Textbook Distribution and Printing Press; 2011. P. 22-7. [In Persian]. 